\title{
The Many Manipulations of Morty Mouse: Children's Stories and the Parental Encouragement of Altruism
}

\author{
Craig T. Palmer \\ Jennice Wright \\ Scott A. Wright \\ Chris Cassidy \\ Todd L. VanPool
}

See next page for additional authors

Follow this and additional works at: https://bearworks.missouristate.edu/articles-coe

\section{Recommended Citation}

Palmer, Craig T., Jennice Wright, Scott A. Wright, Chris Cassidy, Todd L. VanPool, and Kathryn Coe. "The many manipulations of morty mouse: Children's stories and the parental encouragement of altruism." Journal of Anthropological Research 62, no. 2 (2006): 235-257.

This article or document was made available through BearWorks, the institutional repository of Missouri State University. The work contained in it may be protected by copyright and require permission of the copyright holder for reuse or redistribution.

For more information, please contact BearWorks@library.missouristate.edu. 


\section{Authors}

Craig T. Palmer, Jennice Wright, Scott A. Wright, Chris Cassidy, Todd L. VanPool, and Kathryn Coe 


\title{
THE MANY MANIPULATIONS OF MORTY MOUSE Children's Stories and the Parental Encouragement of Altruism
}

\author{
Craig T. Palmer \\ University of Missouri-Columbia, Department of Anthropology, 107 Swallow Hall, \\ Columbia, MO 65211-1440,palmerct@missouri.edu \\ Jennice Wright \\ Auxvasse School District, MO \\ Scott A.Wright \\ Columbia School District, MO \\ Chris Cassidy and Todd L. VanPool \\ Department of Anthropology, University of Missouri-Columbia \\ Kathryn Coe \\ Mel and Enid Zuckerman Arizona College of Public Health, Arizona Cancer Center, \\ University of Arizona
}

Most analyses of children's stories share the assumption that stories are told to children to influence their behavior. This paper explores how the analysis of stories can provide insight into social strategies used by people interacting within their cultural context. To demonstrate the potential of this approach, we created multiple versions of an original children's story to explore attitudes of college students toward the form of social interaction known as reciprocal altruism. Some versions portrayed the protagonist of the story as following a tit-for-tat strategy, while in other versions the protagonist was altruistic toward all the other characters regardless of their past behavior. Subjects read one of the versions and rated it in terms of how likely they would be to read it to a child of the appropriate age. The highest rated version involved the protagonist being altruistic even to characters that had cheated in the past. We discuss this finding and suggest future applications of this methodology.

KEY WORDS: Children's stories; Culture; Indirect reciprocal altruism; Parental behavior; Reciprocal altruism; Tit-for-tat strategy

STORYTELLING IS A HUMAN UNIVERSAL (Brown 1991). There is consensus among most of those who study stories designed for children that one of their most important, if not primary, purposes is to teach children the morals of their parents, religion, 
and/or society and, in doing so, influence their behavior (Carpenter 1985; Hunt 1999; Paul 1990; Sarland 1999; West 1999; Wooden 1986; Zipes 1991). There is less agreement concerning the desired effect of children's stories on a child's behavior, and the apparent lessons to be learned from stories often seem to change over time. For example, in recent years, many traditional European stories (e.g. Grimm's Fairy Tales) have been softened in terms of the consequences characters suffer for wrong behavior. Further, the entire point of some stories has been reversed in newer versions of old stories, as is the case with The Little Mermaid. The original version emphasized the importance of a daughter obeying her father's wishes regarding the choice of a husband by having the daughter's failure to obey her father result in her death and transformation into sea foam. In the more recent Disney version the disobedient Mermaid lives happily ever after with her chosen husband while her father apologizes for trying to run his daughter's life. A similar change can be seen in stories regarding reciprocal altruism and how to deal with "freeloaders." In older versions of the story The Little Red Hen/The Wise Hen, freeloaders are cut off from further cooperative interactions, apparently encouraging tit-for-tat behavior. In contrast, protagonists in recent stories (such as David Kirk's Miss Spider's Sunny Patch Kids) continue to be altruistic toward not only freeloaders but even individuals who repeatedly attempt to kill them. Such changes in the moral lessons of stories clearly reflect important changes in values among at least some members of society.

Our goal in the following discussion is to outline a general methodology for using children's literature to identify social values present within groups of people. We apply this methodology to explore the attitudes toward the cultural construct of social altruism among undergraduate students at seven universities in the United States. We then argue that the use of children's literature as a teaching aid for social interactions and the rules that are reflected in such stories can be understood using an evolutionary approach, but only if that evolutionary approach is expanded to include such cultural variables as the influence of parents on the behavior of their children.

\section{CHILDREN'S STORIES AS A MEANS OF INFLUENCING BEHAVIOR}

Scholars studying narratives for children using a variety of approaches and data sets report that these stories are used to influence the values and behavior of children. The ethnographic literature is filled with traditional stories stressing the importance of proper social, or moral, behavior. Keith Basso writes that the stories of the Western Apache "promote compliance with standards for acceptable social behavior and the moral values that support them" (Basso 1990:103). Among the Dogon, Geneviève Calame-Griaule writes that "every narrative is a pretext for a lesson in social ethics. . . I It is the story's most obvious feature" (Calame-Griaule 1986:570). She notes that narratives are referred to as "advice through the wondrous stories of bygone days." In East Africa, girls learned the "secrets of a successful marriage" how to manage males - through stories (Barongo 1997:10). Among the Sami, stories formed the basis of the entire education system across the lifespan; by 
listening to stories they "learned their history, culture, values, world view, norms, rituals, and skills needed in everyday life" (Kuokkanen 1998:11).

A. P. Elkin provides a specific example of how the words of ancestors, especially in the form of stories, instruct countless generations about the rules of social behavior. During initiation rituals Australian Aboriginal stories are told about the ancestral heroes who lived in the Dreamtime, and how they are models for correct social behavior:

At the conclusion of each act [addressing an incident in the life of the hero], which usually lasts only five or ten minutes or so, the old men explain it and the decoration and symbols to any newly initiated men present or to any whose memories need refreshing. In this way, tribal history is handed down, and the patterns of life which the myths enshrine are instilled into the minds of the younger men present, for most do today what the great heroes did in the dream time (Elkin 1964:156).

Peter Hunt writes that children's stories “are overtly important educationally and commercially - with consequences across culture, from language to politics: most adults, and almost certainly the majority in positions of power and influence read children's books as children, and it is inconceivable that the ideologies permeating those books had no influence on their development" (Hunt 1999:1). This influence has been going on since the advent of the printed word, and before that in the form of oral traditions for thousands, and in some cases perhaps tens of thousands, of years. In China, when oral literature (including rhymes, tongue twisters, and jokes) was finally written down in the twentieth century, "every region was found to have its own repertoire of traditional rhymes for children, the subject and the types of which are very similar to those we know in English" (Scott 1980:4).

Among the earliest printed children's books was English printer William Caxton's edition of Fables of Aesop (1483), which "was a favorite text in medieval schools, where the Latin fables had long been used to teach language and rhetoric in combination with sound practical morality" (Wooden 1986:3). Less than one hundred years later John Foxe's Book of Martyrs (1563) was being widely used by parents, clergy, and teachers to point "little feet down the path of righteousness" (Wooden 1986:8). In France, "the literary fairy tale was used as a vehicle to discuss proper breeding and behavior exemplified by models drawn from the practice in court society and bourgeois circles and the theoretical writings on manners" (Zipes 1991:31). In Germany, the Brothers Grimm stories "draw conscious attention to prescribed values and models. As children read or are read to, they follow a social path, learn role orientation, and acquire norms and values" (Zipes 1991:57). In essence, no matter the culture, "At its point of origin for children the literary fairy tale was designed both to divert as amusement and instruct ideologically as a means to mold the inner nature of young people" (Zipes 1991:18).

The use of children's literature to teach morality and the proper rules of social interaction has continued into our own century. There has even been a sense of some obligation on the part of children's books to provide a moral passageway for 
children. "Very often, children's literature is seen as the last repository of the dulcis et utile philosophy: the books may be pleasant, yes, but essentially they have to be useful" (Hunt 1999:11). Humphrey Carpenter writes that while children want stories where the "petty restrictions of real life are removed" (1985:1), adults "are more likely to want to feed the children a set of moral examples. By all means let them have their fun, but the opportunity of providing models of ideal behaviour is not to be wasted" (Carpenter 1985:1).

Children's stories have long been recognized as an important tool in promoting political ideology as well. "In order to respond to what was seen as the bias in children's fiction, it was argued that books should be written with working-class, or female or black protagonists. In this way, working-class, anti-racist and antisexist values would be promoted" (Sarland 1999:42). Feminist theorists historically view children's literature as a way to teach children, especially little girls, to accept their marginalized place in society. Lissa Paul writes:

There is good reason for appropriating feminist theory to children's literature. Both women's literature and children's literature are devalued and regarded as marginal or peripheral by the literary and educational communities. . . . Children, like women, are lumped together as helpless and dependent; creatures to be kept away from the scene of the action, and who otherwise ought not be seen or heard (Paul 1990:149-50).

Marxists see children's literature as an effective tool of the bourgeois to keep the working classes under their thumb. Hitler also recognized the potential power of children's stories. According to Zipes, "The very fact that the Nazis recognized the necessity to create a policy with regard to folk and fairy tales demonstrated a general awareness about their cultural impact on children and adults alike" (1991:135).

In psychoanalytic criticism, although the focus is often on the way children's literature is a chance for the author to work out some of his or her own unresolved conflicts, there is recognition that children's literature can be used to teach and influence the behavior of children. Bruno Bettelheim writes that fairy tales - which he categorizes as separate from, and superior to, children's literature (1976:130-35) but which we would argue are one form of traditional stories - deal "with universal human problems, particularly those which preoccupy the child's mind, these stories speak to his budding ego and encourage its development, while at the same time relieving preconscious and unconscious pressures" (Bettelheim 1976:6). Put another way, in classical Freudian theory, the superego is not present at birth and therefore the child has no sense of the moral standards that govern his or her culture:

Included among the forces that contribute to the formation of the superego is children's literature. The authors of this type of literature often write with the intention of perpetuating their moral values. Similarly, when adults provide a youngster with a children's book, they may hope that the child will absorb the moral dictates that it contains. Thus, as one of the media 
through which a community's moral standards are communicated from one generation to the next, children's literature can play an important role in the process of child rearing (West 1999:152).

It may be only in the argument against censorship that there seems to be an inclination to downplay the influence of children's stories:

Throughout the history of children's literature, the people who have tried to censor children's books, for all their ideological differences, share a rather romantic view about the power of books. They believe, or at least profess to believe, that books are such a major influence in the formation of children's values and attitudes that adults need to monitor nearly every word that children read (West 1996:506).

While we can certainly understand the desire to discourage censorship, we find it rather incongruent that in the preceding quote West contends that children's literature plays an important role in forming the superego.

Thus, except when arguing against censorship, it appears there is wide acceptance of the basic premise that children's stories are a means of teaching and influencing behavior. Many evolutionary psychologists and evolutionary anthropologists concur (Scalise Sugiyama 2001a, 2001b, 2002; Steen and Owens 2001; Tooby and Cosmides 2001; Vaughn 1978; for an exception to the view that stories have an evolved function see Pinker 1997). Although some stop at the general observation that literary narratives reflect our "evolved human mind" and our "complex cognitive adaptations" (Henrich and Boyd 1998:217; see also Daly and Wilson 1999; Gottschall 2002, 2003, 2005; Gottschall et al. 2004, 2006, Scalise Sugiyama 2001a, 2001b), others argue that the information contained in stories has evolutionary significance and that storytelling is part of the human adaptation.

The general evolutionary prediction is that stories should encourage behaviors that helped our ancestors survive and reproduce in the past. For example, Scalise Sugiyama has proposed that "By substituting verbal representations for potentially costly first-hand experience, narrative enables an individual to safely and efficiently acquire information pertinent to the pursuit of fitness in local habitats. If this hypothesis is true, narrative should be rich with information useful to the pursuit of fitness" (2001b:221; see also De Laguna 1997). Some stories influence children to become more efficient foragers (Scalise Sugiyama 2001b) and others encourage behavior likely to decrease the chances of being harmed by nonhuman predators (Scalise Sugiyama 2002). Using the same logic, others (Coe et al. 2005a, 2005b; Coe and Palmer 2006) have argued that stories will concern the most important, unpredictable, and potentially dangerous aspect of the human ancestral environment - other humans. As to the exact nature of this influence on the behavior of those who listen to the stories, Alexander (2005) proposes that the arts, including literature and, more generally, stories, evolved to make "contributions to our patterns of social scenario building through consciousness and foresight" (Alexander 2005:29). These scenarios, he continues, "are obligate passports to social success" 
(Alexander 2005:29). This is similar to Maynard Smith's observation (1984:12) that the function of myths (by which he means traditional stories) "is to give moral and evaluative guidance" and myths are repeated "to persuade others to behave in certain ways" (1984:12; emphasis added; see also Benjamin 1973; Coe 2003; Hefner 1991; Malinowski 1931; Steadman and Palmer 1997).

As a result of their significance, stories are an ideal means of studying the behavior systems that humans in different cultures employ. We undertake such a study by focusing on alternative social strategies related to reciprocal altruism reflected in college students' preferences for different versions of the same story.

\section{RECIPROCAL ALTRUISM}

Reciprocal altruism (Trivers 1971) is an evolutionary concept used to explain altruism among individuals who may or may not be closely related. It simply states that altruistic acts could be favored by natural selection when they are likely to be reciprocated in a form that is at least as valuable to the inclusive fitness of the altruist as the original act was costly. Reciprocal altruism likely has played a major role in human social life for tens (if not hundreds) of thousands of years. The specific tactics of how to come out ahead in reciprocally altruistic interactions have been a major topic of game theorists, and there continues to be disagreement over many aspects of reciprocal altruism. However, some form of a "tit-for-tat" strategy of being altruistic to everyone in the first interaction, but only continuing to be altruistic to those who reciprocated in the past, is often seen as an evolutionarily successful strategy (Ridley 1996). There is also considerable evidence of specific psychological mechanisms, both emotional and cognitive, designed to engage successfully in reciprocally altruistic relationships. Perhaps the best known of these is the "cheater detection" module (Tooby and Cosmides 1992), which presumably evolved to help humans avoid the risks of being repeatedly cheated by someone who does not reciprocate. There is, however, evidence that reciprocal altruism is not left to these mechanisms alone; cultures differ in how and under what circumstances people engage in reciprocal altruism (Henrich et al. 2005). As part of the enculturation process, parents spend a great deal of time and effort instructing their offspring on how to be a good reciprocal altruist. For example, telling children always to say "thank you" is clearly aimed at helping the child form reciprocally altruistic relationships (Barber 2004).

The importance of reciprocal altruism in human social life, and the clear encouragement of this type of behavior by parents, leads to the prediction that the culturally specific rules of reciprocal altruism should be a common theme in children's stories. The apparent existence of evolved psychological mechanisms designed to deal with reciprocal altruism raises the interesting question of whether children's stories intensify and reinforce these mechanisms or offset them and weaken their effects based on one's cultural context. This question is further complicated by the fact that indirect reciprocal altruism (Alexander 1987) has also played a major role in human social life; our altruistic (or nonaltruistic) acts influence future interactions not only with the actual recipients of our altruism, but 
also with individuals merely observing our interactions. The advantages of creating such a "reputation" for being an altruist could encourage others to be altruistic toward one, given that they can reasonably expect to have their altruism reciprocated, and thereby can explain greater degrees of altruism than would be predicted by direct reciprocal altruism alone.

Given this complex situation, it seems safe to predict that children's stories should often concern reciprocal altruism. However, it isn't clear exactly what message should be encouraged by stories, because there are at least three possibilities:

1. Stories could reinforce existing cheater-detection mechanisms and encourage the discrimination against nonaltruists needed for a tit-fortat strategy.

2. Stories could partially offset or soften the cheater-detection mechanisms and emotions by encouraging indiscriminate altruism.

3. Stories could encourage children to be subtle in their discrimination against nonaltruists, and instruct them on how to accomplish this.

All three of these possibilities are worth considering because they all lead to potential benefits. The benefit to hypothesis 1 is the avoidance of being altruistic to nonreciprocators. The benefit to hypothesis 2 is to reap the indirect reciprocal altruism benefits that come from establishing a reputation of being an altruist. The benefit to hypothesis 3 is a mixture of the first two, avoiding being altruistic toward nonreciprocators while maintaining a reputation for being an altruist by camouflaging their tit-for-tat, cheater-detection pattern of behavior. Within different cultural contexts any of these alternatives might be favored, and within any single cultural context, individuals may differ in which of these alternatives they generally employ. This possibility is demonstrated by the previously mentioned tendency for the point of children's stories to change over time.

Another question concerns whether stories about reciprocal altruism will include acts of altruism being reciprocated. The inclusion of reciprocation in stories might motivate children to engage in acts of altruism in a desire to receive the benefits. However, there are two reason why this may not be the case. First, if one's concern about reciprocation is too obvious, it might lead to a nonaltruistic reputation (i.e., the perception that one's altruism comes at a price). Second, although reciprocal altruism is often described as involving the benefits coming back to the individual, what is actually "evaluated" by natural selection is the effect of altruism on the future frequency of the genes of the altruist. A life of sustained altruism might be selected for if the acts are reciprocated to one's descendants instead of oneself. As Achsah Carrier observed among the Ponam of New Guinea, "the idea that present sacrifice leads to future reward falls to the ground, as Ponams themselves admitted, because realistic expectations of the future [were of] . . . a future of more self-sacrifice rather than future material benefits from present abstention" (Carrier 1987:158). Hence, either stories may directly encourage such sustained lifelong altruism, or they may lead individuals indirectly into such a life by promising rewards to the individual, in a way analogous to the promise of living happily ever after. 


\section{EXISTING STORIES INVOLVING RECIPROCAL ALTRUISM}

One obvious method of gaining insight into the role of children's stories is to examine existing stories. The strengths of this approach include dealing with actual stories produced and repeated by human parents, often for many generations. This approach, especially when applied across different cultures and historical periods, can potentially test many specific predictions, especially when multiple versions of a story are encountered. In such cases, it might be possible to correlate the different versions with specific social variables.

Reciprocal altruism is a common theme found both cross-culturally and diachronically in children's stories. Classical stories about altruism have demonstrated great staying power even as newer, more culturally relevant altruism stories arise, and Western parents now increasingly seek stories from other cultures, including Japanese, African, East Indian, and Native American traditions.

However, different versions of the same story and translation difficulties make subtle distinctions about the exact messages of these stories unclear. An examination of children's literature finds examples of both stories that encourage discriminating, tit-for-tat altruism (where the discrimination may be either obvious or subtle) and stories that encourage an indiscriminate altruism toward other characters regardless of their past behavior. In some stories the altruist's good deeds are reciprocated, and in others they are not.

Stories illustrating indiscriminate altruism often include young men performing heroic deeds. In Jack the Giant Killer, a classic English fairy tale retold by Joseph Jacobs, Jack ventures his life to kill giants and rescue young ladies. The king rewards Jack for his altruistic behavior by allowing him to marry his daughter, and by giving him a castle and an estate (Rackham 1974). Cesarino and the Dragon, translated and retold by G. W. Waters, is a classic Italian example of a similarly heroic young man who is rewarded with the princess he saves (Rackham 1974).

Also common among stories of the indiscriminate altruist are characters that are asymmetrically rewarded for very small acts of kindness. In the Hindu tale Matsaya, young Manu saves the life of a little fish that then grows large and warns Manu to prepare for a flood by building a large boat and filling it with all plants, seven wise men, and animals two by two. The fish then tows the boat to the Himalayas, and creates a wife for Manu. Manu and his wife become the ancestors of the Hindus (Shepherd 1995). By saving the life of a little fish, Manu is rewarded with boundless reproductive success. Similar asymmetrical rewards are also found in J. F. Cambell's retelling of the Scottish tale Battle of the Birds, wherein a young man who saves the life of a raven is rewarded with an enchanted castle (Rackham 1974).

Stories in which the reciprocated altruist is either subtly or obviously discriminating also abound and often include an open exchange between characters outlining how they will help each other. In Lord Redesdale's translation of a classic Japanese tale, Little Peachling gives away millet dumplings to a hungry ape, pheasant, and dog in exchange for their accompanying him to an ogre's island where they are to help Little Peachling capture the ogre's riches (Rackham 1974). An obvious exchange of altruism also occurs between the characters of Aesop's 
fable The Lion and the Mouse. The hungry lion heeds the mouse's plea, "If you don't eat me, one day you might need my help!" In return, the mouse later chews through a rope to save the lion's life (Piumini 1989:20).

Other stories do not contain any altruistic acts at all, and simply instruct children on who not to trust (or be altruistic toward), and how to handle cheaters. For example, in stories like The Little Red Hen, Aesop's The Cicada and the Ants, the Japanese tale The Tongue Cut Sparrow, and the African tale The Animals Share, lazy and nonaltruistic characters are openly punished or are not shared with (Hamilton 1997; Piumini 1989; Quattrocki 1995; Rackham 1974). As previously mentioned, the most explicative of these is The Little Red Hen, whose friends would not help her plant, tend, harvest, or mill her wheat. Nor would they help her bake bread. In response to her hungry friends, who had refused to help, the calculating Little Red Hen says, "All these things I did by myself. Now my chicks and I will eat this bread by ourselves!" (Quattrocki 1995).

As Daly and Wilson so aptly point out, when the same theme is found in stories from a multitude of cultures, "those themes must have something to do with the human condition" (1999:5). However, although occurrences of reciprocal altruism may be part of the human condition, there are clearly cultural and temporal differences in the exact circumstances under which reciprocal altruism is considered appropriate. Thus, a cross-cultural study of children's literature can provide excellent insight into the range of variation in human behavior, but more focused studies are needed to understand the social rules within specific cultures.

One means of studying the rules regarding reciprocal altruism would be to look at the range of stories within a specific culture. Another approach, and the one that we employ here, is instead to provide a new story and monitor people's reactions to it. When compared with a survey of existing literature, the second approach has several advantages in that specific issues of behavior can be highlighted within the story, thereby decreasing the subjectivity of determining what "the point of the story" might be. Also, different versions of the same story can help provide a more nuanced view of the social rules in a particular cultural context, which may not be possible by relying only on literature that currently exists. Although we apply this approach in the context of seven U.S. universities, we argue that it is generally applicable in anthropological contexts.

\section{IDENTIFYING VALUES BY MANIPULATING AN ORIGINAL STORY}

To get at current views concerning the role of reciprocal altruism among college students, a subset of the larger American culture, we created six versions of an original children's story entitled Morty Mouse Leaves Home (see Appendix). Although written specifically for this study, our story is based on elements often found in traditional children's stories. Our story not only deals with altruism, it follows the familiar theme whereby "initially the young protagonist must leave home or the family" (Zipes 1991:57).

Subjects for the study were 555 undergraduate students in classes at one of seven universities in the United States (University of Colorado-Colorado Springs 
[ $n=194]$, Arizona State University [ $n=145]$, University of California at Berkeley $[n=76]$, University of Wyoming [ $n=51]$, University of Minnesota [ $n=49]$, University of Connecticut [ $n=27]$, and Hofstra University [ $n=13])$. The survey was administered during the mid-1990s and the entire data set was analyzed together in order to obtain a large enough sample to detect statistically significant findings. There were 374 female subjects and 181 male subjects, of whom 51 of the women and 22 of the men reported being parents. The average age of male subjects was 23.24 (s.d. $=7.23$ ) and the average age of female subjects was $23.10($ s.d. $=6.87)$. Students in American universities are obviously not representative of all humans, and we strongly encourage future cross-cultural studies. We also suggest that future studies include larger samples of parents. However, one advantage to our samples is that most subjects were at or near the age at which humans often become parents and start influencing their children by telling stories to them.

Subjects read one of six randomly distributed versions of our original story. Subjects were informed that their participation in the study was voluntary and would not affect their course grade in any way. They were also informed that, in order to maximize confidentiality, they were not to provide their names on the instrument and that only aggregate data from the study would be published. They were also informed that returning the completed survey would indicate their consent to being part of the study. The subjects were then asked to use a scale of $1-10$ to rate how likely they would be to read the story they had just read to an appropriately aged child, with 10 being most likely to read and 1 being least likely to read.

To help ensure that any differences in preference were due to the different descriptions of altruism, only a few words were changed in each version of the story. Respondents were asked to give the reasons for their ratings, and these responses provided no evidence that the versions differed in any way other than the variables related to altruism just described. Subjects were also asked to rate the overall entertainment level of the story to make sure that it was not influencing their rating. The entertainment level ratings were relatively high for all versions of the story (average of 6.4 with a standard deviation of 2.11), and there were no statistically significant differences in this rating between the different versions.

The story first introduces the reader to two characters (Priscilla Partridge and Bartholomew Bunny), who had been altruistic to Morty Mouse and his family in a time of need, and one character (Thomas Toad) who had not, despite the fact that Morty's family had been altruistic to him. It then tells how Morty later leaves home and encounters these three characters again, finding them in need. Bartholomew Bunny was hungry, but he could be fed if Morty gave Bartholomew his seed grain. Priscilla Partridge's nest was damaged by wind, but it could be repaired if Morty gave her the yarn that he was going to use to knit his winter clothes. Thomas Toad was cold because of the rain, but he could be warmed if Morty gave him the wood with which Morty was going to build his home. In each case Morty was forced to make a decision about whether or not to act altruistically.

As mentioned, subjects read one of six different versions of the story and then rated it on a scale of one to ten in terms of how likely they would be to read it to a child of the appropriate age. In all of the versions, Morty was a good reciprocator 
and altruistically assisted the two characters (Priscilla Partridge and Bartholomew Bunny) that had previously assisted him. In version 1, the calculating version, Morty refused Thomas Toad's request explicitly because he had not reciprocated past altruism. In version 2, the subtly calculating version, Morty subtly refused Thomas Toad's request without explicitly stating his reason for refusal. In version 3 , the indiscriminate version, Morty acted altruistically toward all three characters.

If the subjects favor encouraging a strict tit-for-tat strategy that reinforces our "cheater detection" modules, subjects should prefer a version of the story where Morty explicitly (version 1) or subtly (version 2) refuses to help Thomas because of his previous lack of altruism. If they prefer stories that encourage children to be subtle in this discrimination, version 2 should be the most preferred version. On the other hand, if subjects prefer stories that encourage altruism in a way that partially offsets the cheater detection module and related mechanisms (perhaps to benefit from indirect reciprocal altruism), then they would prefer version 3 where Morty ignores Thomas's past behavior and treats him as altruistically as the other characters.

We provided two alternative endings for each of these three versions of the story: ending A, in which Morty is a "winner" because he is repaid by those he aided, and ending B, in which Morty is a "loser" because his altruism is not reciprocated (see Appendix). Thus, we ended up with six versions of the storycalculating winner, calculating loser, subtly calculating winner, subtly calculating loser, indiscriminate winner, and indiscriminate loser. All six versions end with Morty living happily ever after, either because his altruism was reciprocated or because his "heart was warm" for having given to his friends.

\section{RESULTS}

Each version of the story was read by between 89 and 96 subjects. The ratings for how likely subjects would be to read each story to an appropriately aged child (scored on a scale of 1-10) were condensed into three categories in order to maximize the sample size. The categories were as follows:

1,2 , and 3 were classified as "Unlikely to read."

$4,5,6$, and 7 were classified as "Somewhat likely to read."

8,9 , and 10 were classified as "Likely to read."

A chi-square analysis was used to evaluate the likelihood that people who read the various versions would read them to their children. The chi-square analysis, presented in Table 1, indicates significant differences in the likelihood of reading each story $(\alpha=.05)$. (An adjusted residual larger than 1.96 or smaller than -1.96 is statistically significant at the .05 level of rejection. A negative sign reflects that fewer than expected indicated that level of likelihood, whereas a positive value indicates that more than expected selected that level of likelihood. Bolded values are statistically significant.) An analysis of the chi-square adjusted residuals indicates that the "calculating loser" version of the story was less likely to be read 
than the other versions. In this version Morty withholds his resources from the treacherous Thomas Toad explicitly because the Toad had not reciprocated in the past, and Morty does not receive reciprocation from the other characters that he helps. Further, fewer people were unlikely to read the "indiscriminate winner" version than the other versions (i.e., people preferred the "indiscriminate winner" version). In this version, Morty shares his resources with all three of the characters, and Priscilla Partridge and Bartholomew Bunny reciprocate Morty's generosity.

TABLE 1

Chi-square analysis of likelihood to read the six versions of the story

\begin{tabular}{|c|c|c|c|c|c|}
\hline Likelihood to Read & Story Version & Observed & Expected & $\chi^{2}$ & $\begin{array}{l}\text { Adjusted } \\
\text { Residuals }\end{array}$ \\
\hline \multirow[t]{6}{*}{ Unlikely } & Calculating Winner & 14 & 11.2 & 0.69 & 0.97 \\
\hline & Calculating Loser & 21 & 12.1 & 6.53 & 3.01 \\
\hline & Subtly Calculating Winner & 12 & 11.6 & 0.01 & 0.14 \\
\hline & Subtly Calculating Loser & 7 & 11.5 & 1.75 & -1.55 \\
\hline & Indiscriminate Winner & 6 & 11.9 & 2.89 & -2 \\
\hline & Indiscriminate Loser & 10 & 11.7 & 0.26 & -0.59 \\
\hline \multirow[t]{6}{*}{ Somewhat Likely } & Calculating Winner & 29 & 34.3 & 0.82 & -1.26 \\
\hline & Calculating Loser & 41 & 37 & 0.43 & 0.92 \\
\hline & Subtly Calculating Winner & 31 & 35.5 & 0.56 & -1.05 \\
\hline & Subtly Calculating Loser & 40 & 35.1 & 0.69 & 1.16 \\
\hline & Indiscriminate Winner & 36 & 36.2 & 0 & -0.06 \\
\hline & Indiscriminate Loser & 37 & 35.9 & 0.04 & 0.27 \\
\hline \multirow[t]{8}{*}{ Likely } & Calculating Winner & 46 & 43.5 & 0.15 & 0.59 \\
\hline & Calculating Loser & 34 & 46.9 & 3.54 & -2.89 \\
\hline & Subtly Calculating Winner & 49 & 44.9 & 0.37 & 0.93 \\
\hline & Subtly Calculating Loser & 44 & 44.4 & 0 & -0.1 \\
\hline & Indiscriminate Winner & 52 & 45.9 & 0.81 & 1.38 \\
\hline & Indiscriminate Loser & 46 & 45.4 & 0.01 & 0.13 \\
\hline & \multicolumn{3}{|l|}{$\chi^{2}$} & \multicolumn{2}{|l|}{19.54} \\
\hline & \multicolumn{3}{|l|}{ Critical Value $(.05,10)=$} & \multicolumn{2}{|l|}{18.31} \\
\hline
\end{tabular}

The result of a chi-square analysis comparing the likelihood of reading the story among only those subjects who were not parents is presented in Table 2 . The chi-square analysis indicates a significant difference $(\alpha=.05)$, and an analysis of the adjusted residuals indicates that the indiscriminate winner and, especially, the subtly calculating winner, in which Morty does not share his resources with the perfidious Toad without giving an explicit reason, were more likely to be read than the other version. The calculating loser had more extremely negative responses than the other versions, although this difference was not statistically significant.

We also evaluated the null hypothesis that there was no difference in the likelihood that those who were already parents would read one of the six versions to their children using Pearson's exact probability test. (Small sample size prevented 
TABLE 2

\section{Chi-square analysis comparing the likelihood of reading} the story among those without children

\begin{tabular}{llcccc}
\hline \multirow{2}{*}{ Likelihood to Read } & Story Version & Observed & Expected & $\chi^{2}$ & $\begin{array}{c}\text { Adjusted } \\
\text { Residuals }\end{array}$ \\
\hline Unlikely & Calculating Winner & 22 & 19.9 & 0.23 & 0.61 \\
& Calculating Loser & 28 & 21.7 & 1.83 & 1.73 \\
& Subtly Calculating Winner & 18 & 19.6 & 0.13 & -0.46 \\
& Subtly Calculating Loser & 19 & 21.2 & 0.22 & -0.6 \\
& Indiscriminate Winner & 12 & 21.7 & 4.33 & $-\mathbf{2 . 6 6}$ \\
Somewhat Likely & Indiscriminate Loser & 27 & 22 & 1.16 & 1.38 \\
& Calculating Winner & 31 & 35 & 0.46 & -1 \\
& Calculating Loser & 38 & 38.2 & 0 & -0.06 \\
& Subtly Calculating Winner & 28 & 34.5 & 1.24 & -1.65 \\
& Subtly Calculating Loser & 39 & 37.3 & 0.08 & 0.41 \\
& Indiscriminate Winner & 50 & 38.2 & 3.62 & $\mathbf{2 . 8 5}$ \\
& Indiscriminate Loser & 36 & 38.7 & 0.19 & -0.65 \\
& Calculating Winner & 23 & 21.1 & 0.17 & 0.52 \\
& Calculating Loser & 17 & 23.1 & 1.6 & -1.64 \\
& Subtly Calculating Winner & 29 & 20.9 & 3.19 & $\mathbf{2 . 2 9}$ \\
& Subtly Calculating Loser & 23 & 22.5 & 0.01 & 0.13 \\
& Indiscriminate Winner & 21 & 23.1 & 0.19 & -0.56 \\
& Indiscriminate Loser & 21 & 23.4 & 0.24 & -0.63 \\
\hline & $\chi^{2}=$ & & 18.88 & \\
& Critical Value (.05, 10) $=$ & & & 18.31 & \\
\hline
\end{tabular}

us from using a chi-square test: 14 of the cells [about $78 \%$ of them] had expected frequencies less than 5 , which violates the commonly accepted assumption of the chi-square test requiring that at least $80 \%$ of the cells have expected frequencies of 5 or more [Cochran 1954:420; see also Bernard 1994:438, 442; Drennan 1996:19698; Rose and Altschul 1988:197; Shennan 1990:71; Thomas 1986:298].) The resulting probability is .16 (which is larger than our alpha of .05), and we cannot reject the null hypothesis. Our sample of 73 parents may simply not be large enough to detect any differences that might be present.

Next we compared the likelihood of reading the stories among women and among men and found that there was no statistically significant difference in either group $(\alpha=.05)$. None of the versions are substantially preferred over the others within each sex. Given that we do see differences in the likelihood of reading the stories within the combined sample, this lack of significant differences reflects the result of the decreased sample size caused by separating men and women.

We next evaluated the effect on the likelihood of reading the story of Morty's decision whether or not to discriminate against Thomas Toad. A chi-square analysis was again used to evaluate the null hypothesis that there is no difference in the likelihood of reading any of the story versions, this time dividing the stories by 
Morty's choice. The chi-square analysis, presented in Table 3, indicates significant differences in the likelihood of reading the three versions. Readers disliked the calculating version of the story, in which Morty does not aid Thomas Toad explicitly because of the Toad's past lack of altruism. In contrast, readers felt less negatively about the indiscriminate version in which Morty provides help indiscriminately even to Thomas Toad.

TABLE 3

Chi-square analysis of likelihood to read the versions based on Morty Mouse's decision to help Thomas Toad

\begin{tabular}{|c|c|c|c|c|c|}
\hline Likelihood to Read & Level of Discrimination & Observed & Expected & $\chi^{2}$ & $\begin{array}{l}\text { Adjusted } \\
\text { Residuals }\end{array}$ \\
\hline \multirow[t]{3}{*}{ Unlikely } & Calculating & 35 & 23.3 & 5.83 & 3.16 \\
\hline & Subtly Calculating & 19 & 23.1 & 0.72 & -1.11 \\
\hline & Indiscriminate & 16 & 23.6 & 2.44 & -2.05 \\
\hline \multirow[t]{3}{*}{ Somewhat Likely } & Calculating & 70 & 71.3 & 0.02 & -0.25 \\
\hline & Subtly Calculating & 71 & 70.6 & 0 & 0.08 \\
\hline & Indiscriminate & 73 & 72.1 & 0.01 & 0.17 \\
\hline \multirow[t]{5}{*}{ Likely } & Calculating & 80 & 90.3 & 1.18 & -1.86 \\
\hline & Subtly Calculating & 93 & 89.4 & 0.15 & 0.66 \\
\hline & Indiscriminate & 98 & 91.3 & 0.49 & 1.2 \\
\hline & $\chi^{2}=$ & & & 10.85 & \\
\hline & Critical Value $(.05,4)=$ & & & 9.49 & \\
\hline
\end{tabular}

We next compared the preferences of men and women in regard to Morty's choice of whether or not to discriminate against Thomas Toad. The null hypotheses are that there are no differences in the likelihood of reading any of the three versions. The chi-square value for women does not exceed the critical values using an alpha of .05 , and we cannot reject the null hypothesis. However, the chi-square value for men does exceed the critical value for an alpha of .05 (Table 4); an evaluation of the adjusted residuals indicates that men strongly dislike the calculating version of the story (in which Morty explicitly decides to refuse to help Toad) but are less negative about the indiscriminate version (in which Morty shares with Thomas Toad) than expected by chance.

We then collapsed the story versions into two classes - winner and loser- - to evaluate the impact on the likelihood of reading the story of whether Morty's kindness to the other animals was reciprocated. We used a chi-square analysis to evaluate the null hypothesis that there were no differences in the likelihood of reading between the winner variant, in which Morty Mouse's friends Bartholomew Bunny and Priscilla Partridge reciprocate his generosity, and loser variants, in which they do not. The chi-square value does not exceed the critical value, preventing us from rejecting the null hypothesis; there are no apparent differences in the likelihood that someone would read the story based on whether or not Morty was reciprocated at the end of the story across the entire sample. However, when 
TABLE 4

Chi-square analysis of the effect of the level of discrimination

on the likelihood of men to read each version

\begin{tabular}{llcccc}
\hline Likelihood to Read & Level of Discrimination & Observed & Expected & $\chi^{2}$ & $\begin{array}{c}\text { Adjusted } \\
\text { Residuals }\end{array}$ \\
\hline Unlikely & Calculating & 19 & 10.4 & 7.13 & $\mathbf{3 . 5 7}$ \\
& Subtly Calculating & 8 & 11.1 & 0.88 & -1.27 \\
& Indiscriminate & 6 & 11.5 & 2.62 & $\mathbf{- 2 . 2 2}$ \\
Somewhat Likely & Calculating & 19 & 23.3 & 0.79 & -1.4 \\
& Subtly Calculating & 25 & 24.9 & 0 & 0.02 \\
\multirow{5}{*}{ Likely } & Indiscriminate & 30 & 25.8 & 0.7 & 1.35 \\
& Calculating & 19 & 23.3 & 0.79 & -1.4 \\
& Subtly Calculating & 28 & 24.9 & 0.38 & 0.98 \\
& Indiscriminate & 27 & 25.8 & 0.06 & 0.39 \\
\hline & $\chi^{2}=$ & & & 13.35 & \\
\hline
\end{tabular}

we evaluated the impact of the reciprocation of Morty's generosity as reflected by the likelihood of reading the story among women, a statistically significant difference was present $(\alpha=.05)$. The chi-square test indicates that women are more likely to read the "winner" version of the story than the "loser" version (Table 5). Similar differences are not evident among men. Whereas women are less likely to read the "loser" version, men are not.

TABLE 5

Chi-square analysis of the effect of the reciprocity of Morty's friends on the likelihood of women to read each version

\begin{tabular}{|c|c|c|c|c|c|}
\hline Likelihood to Read & $\begin{array}{l}\text { Story } \\
\text { Version }\end{array}$ & Observed & Expected & $\chi^{2}$ & $\begin{array}{l}\text { Adjusted } \\
\text { Residuals }\end{array}$ \\
\hline \multirow[t]{2}{*}{ Unlikely to Read } & Winner & 13 & 17.6 & 1.21 & -1.6 \\
\hline & Loser & 24 & 19.4 & 1.1 & 1.6 \\
\hline \multirow[t]{2}{*}{ Somewhat Likely to Read } & Winner & 59 & 66.6 & 0.87 & -1.63 \\
\hline & Loser & 81 & 73.4 & 0.79 & 1.63 \\
\hline \multirow[t]{4}{*}{ Likely to Read } & Winner & 106 & 93.8 & 1.6 & 2.54 \\
\hline & Loser & 91 & 103.2 & 1.45 & -2.54 \\
\hline & \multirow{2}{*}{\multicolumn{3}{|c|}{$\begin{array}{l}\chi^{2}= \\
\text { Critical Value }(.05,2)=\end{array}$}} & 7.02 & \\
\hline & & & & 5.99 & \\
\hline
\end{tabular}




\section{DISCUSSION}

The study found the following statistically significant results:

1. Readers preferred the version of the story in which Morty indiscriminately helped the ungrateful toad while also having his generosity to the other animals reciprocated (indiscriminate winner). The least likely version of the story to be read was the version in which Morty refused to help Thomas Toad explicitly because Morty remembered the toad's refusal to reciprocate in the past, while also not having his generosity to the other animals reciprocated (calculating loser).

2. The subtly calculating and, especially, indiscriminate versions of the story were preferred over the calculating version of the story. Men especially disliked the calculating version of the story (in which Morty explicitly decides to withhold his resources from the treacherous toad) while preferring the indiscriminate version (in which Morty shares with Thomas Toad).

3. Women are less likely to read the "loser" version of the story in which his friends do not reciprocate Morty's generosity. This preference is not evident among men.

The preference for story versions that emphasize helping others indiscriminately, even when that help had not been reciprocated in the past, would seem to indicate that our second prediction, that the subjects want stories to encourage children to be indiscriminately altruistic, is dominant within the cultural context of the college students. If this is indeed found to be the case more generally among the broader human population, then one function of children's stories may be to partially offset or soften the cheater-detection mechanisms and emotions by encouraging indiscriminate altruism. An advantage of this would be to reap the indirect reciprocal altruism benefits that come from establishing a reputation of being an altruist (Alexander 1987). Such a finding would demonstrate the importance of including cultural behavior (i.e., the influence of parents on the behavior of their children) in evolutionary models and would provide a clue to some of the specific influences of such cultural behavior. However, numerous other possibilities should be investigated in future studies before reaching this conclusion.

We doubt based on our review of children's literature that this emphasis on indiscriminate altruism is uniform through time, across cultures, or in stories aimed at children of different ages. Stories such as The Little Red Hen advocate very different strategies regarding altruism than are preferred among the college students involved in our study. As similar studies are conducted in other cultural contexts, anthropologists should be able to begin to identify the social factors underlying the preferences for each of the alternate strategies. Different stories are likely to be encouraged in different social environments. Further, the age, gender, socioeconomic status, ethnicity, and a host of other characteristics of parents who tell the stories, children who hear the stories, and the story characters might be 
found to influence story preference even within a given social environment. We will discuss only a few of the numerous predictions that could be made about these variables.

In regard to the social environment, we predict that the preference for indiscriminate altruism will be most often found in social environments where the benefits resulting from a reputation for being altruistic are high (see Palmer 1991). When such reputation benefits are high among only certain segments of society, we would also predict a preference for stories like Robin Hood, which would seem to suggest that the benefits of being seen as an altruist by the poor offset the costs of stealing from the rich and powerful. In environments without such reputation benefits, we might expect stories that encourage indiscriminate altruism would be more likely to be encouraged when the altruistic act is aimed toward individuals with plentiful resources who are likely to reciprocate than toward others who possess comparatively fewer resources. Another possibility is that stories in which nonaltruists go unpunished by the offended party might be more popular in societies where the punishment of cheaters has been taken over by the state.

In regard to characteristics of the child hearing the story, future studies should pay particular attention to the developmental stage of the child. Steen hypothesizes that narratives contain characters with "transparent minds" (Cohn 1978) that allow children to see concealed connections between the motivation and action of characters, which in turn helps them develop "mental modeling" skills (Steen 2005). In other words, through a story the thoughts and behavior of the character (or characters) become "hyperintelligible" to the child, hence allowing him or her to learn important lessons while being shielded from real-life consequences. For this reason, stories with clear-cut villains may be more effective in influencing the behavior of younger children, whereas stories with morally ambiguous characters may be aimed at older children. In terms of future studies, we predict a preference for more subtle messages in stories aimed at children old enough to understand such subtle forms of interaction. It is also possible that stories encouraging altruism among characters that are portrayed as being kin may be preferred more by parents with multiple offspring than parents with only one offspring.

In regard to the characters in the story, we predict that portraying Morty as a juvenile dealing with characters that were probably perceived as being more experienced adults (at least in the case of Priscilla Partridge) may have influenced the preference for being indiscriminately altruistic toward adults who might have the power to punish nonaltruistic acts. Clearly a story involving a juvenile female character leaving home would involve many other considerations, especially if portrayed as interacting with adult male characters.

We examined possible influences of both gender and whether or not subjects were parents to explore how these variables might influence preferences for different versions of the story. We predicted that the more "nurturing" role of mothers relative to fathers in American society might lead women to favor more altruistic versions with happier endings, a prediction that received some support from our study. Although we did not have a specific prediction about differences between parents and non-parents, we suspected that the actual experience of being a parent might 
influence preferences in some way. Unfortunately, our sample size probably prevented us from finding any significant differences in terms of this variable.

Finally, game theory suggests that there are other possibilities to consider when investigating all of these variables (Ridley 1996; see Ishii and Kurzban 2005 for an interesting example of a cross-cultural study). This is the possibility that there is an evolutionarily stable mix of different reciprocation strategies in any given population, and that the frequency of each strategy is dependent upon the frequency of other strategies within the population. Although our study did not include enough subjects in the different locations to test this possibility at each location, future studies could be designed to do so. Also, future studies of the influence of local distribution of different reciprocation strategies would need to include a wider age range of subjects in order to have a representative sample of the local environment.

As a universal part of human life, the telling of stories is of obvious interest to researchers attempting to explain human behavior. As we have argued here, these stories can provide significant social information, especially children's literature that commonly is intended to impart morals and demonstrate the consequences of proper and improper behavior. Examining children's literature and using different versions of the same story as we have done here provide anthropologists another means of examining human behavior and the factors that underlie it.

\section{NOTE}

We would like to thank B. Eric Fredrickson and Amber L. Palmer for their assistance during the early stages of this project. We would also like to thank everyone at the University of Colorado-Colorado Springs, Arizona State University, University of Wyoming, University of California at Berkeley, Hofstra University (New York), University of Minnesota, and the University of Connecticut who cooperated in this study. The revised manuscript has profited from the recommendations of four $J A R$ reviewers plus the Editor.

\section{APPENDIX}

We present the first version of the story and indicate the changes made to generate the other five versions below. We also present the questionnaire, which was the same for all six versions of the story.

\section{Version 1: Calculating Winner}

\section{Morty Mouse Leaves Home}

Sometime ago ... in a forest nearby ... a young mouse, Morty Mouse, grew up with his family, friends, and neighbors near Triver's Pond in Steadman's Forest. Morty loved his home in the forest, for there were so many nice animals there. They were such fun to play with, and it seems they always helped each other out whenever someone needed it. One time, after a fire burned part of the forest, all the animals worked together to help each other. That is, all but Thomas Toad.

Bartholomew Bunny dug a burrow so Priscilla Partridge's children could hide. Then, Priscilla Partridge flew to Dawkin's Creek to warn Bartholomew's cousins about the fire. 
Morty's family even let Thomas Toad stay at their house near Triver's Pond. But even though the Mouse family was nice to Thomas Toad, Thomas refused to help the Mouse family protect their house, so part of it burned. Luckily, none of the animals in Steadman's Forest were hurt, and by the following spring, the forest was lush and green again.

That spring, Morty Mouse decided that it was time for him to leave his family's comfy mouse-house to make his way in the world. So Morty's mother and father gathered all the things Morty would need to take with him so he would be prepared for winter. They gathered: grain to plant, harvest, and store so he would have food to eat; beautiful green yarn to knit into a sweater to help him keep warm; and a bundle of wood so he could build his own mouse-house to shelter him. Morty's parents packed these things and sent him on his way with proud hugs and kisses good-bye.

Not far from home, Morty heard Bartholomew Bunny crying loudly in his den. Worried for his friend, Morty stuck his whole head into the den and called "Oh, Bartholomew ... Bartholomew Bunny ... what's wrong?" "I'm . . . I'm soooo hungry!" cried Bartholomew. "I'm out of last winter's grain and my spring carrots aren't ready to harvest yet." Morty felt bad for the hungry bunny, and he remembered that Bartholomew usually repaid his debts, so he gave Bartholomew the grain his parents packed. Bartholomew was so happy he jumped with joy and gave Morty a big hug. "Oh, thank you. Thank you!" blurted the bunny. "How could I ever repay you?" Morty knew that bunnies cooked yummy carrot stew and replied, "When the leaves turn color, fix me a pot of your yummy carrot stew."

Morty felt good as he left Bartholomew's den so he whistled a little tune as he walked. Priscilla Partridge didn't hear him because she was so busy trying to repair her nest that had just been blown down by a strong gust of wind. Indeed, Priscilla was so busy flapping about that she barely even heard him say "Hello." "Oh, my! Oh, my!" squawked Priscilla. "How will I ever repair my nest? My children will be homeless!" Morty saw a rain cloud approaching and was worried for Priscilla and her children. Remembering that Priscilla usually repaid her debts, Morty spoke up, "Hey, Priscilla! I have an idea. Why don't we use my yarn to repair your nest?" Priscilla knew that yarn would do just the trick so she gladly accepted his help. With Morty's help, they finished just in time to snuggle Priscilla's children in before the rain fell. "Thank you so much," sang Priscilla. "How could I ever make it up to you?" "When the days grow shorter," said Morty, "Sew me a beautiful coat," for he knew that partridges sewed beautiful coats.

Morty didn't mind the rain so he kept on walking, but not far from Priscilla's nest he heard Thomas Toad croaking and croaking. "How are you doing?" asked Morty Mouse of Thomas Toad. "Oh, I'm so c-c-c-cold and w-w-wet," croaked Thomas, "I d-d-d-don't think I c-c-can stand it much longer! Why d-d-d-don't you build me a f-f-fire with your bundle of wood?" Morty felt sorry for Thomas, but then he remembered that Thomas never repaid favors so he said, "No, Thomas, but I'll sing you a song so you can hop and dance a jig to keep warm until the rain stops."

[In version 3, "Subtly Calculating Winner," and version 4, "Subtly Calculating Loser," the italicized section is replaced with: Morty felt sorry for Thomas but said, "No, Thomas, but I'll sing you a song so you can hop and dance a jig to keep warm until the rain stops."]

[In version 5, "Indiscriminate Winner," and version 6, "Indiscriminate Loser," the italicized section is replaced with: Morty felt sorry for Thomas so he unpacked his bundle of wood and built a fire to warm and dry the toad. When Morty left, the toad, who was now warm and dry by the fire, didn't even say thank you.] 
Further down the path, Morty reached the edge of Steadman's Forest where he found a perfect patch of meadow. The meadow grass was soft and tall. Nearby ran a stream, and on the edge of that stream grew big sweet juicy-berries. There Morty built a comfy mousehouse. He had plenty of time to take walks into the forest, gather sweet juicy-berries, and daydream for there was no grain to plant, harvest, or store. Nor was there a sweater to knit. There in the meadow, Morty swam in the stream, gathered fresh juicy-berries to eat, and slept in his comfy mouse-house every night through the rest of the spring, summer, and even into the fall.

Green turned to red and gold. Wind followed the arrival of fall which carried down the colorful forest leaves. Not long after, Morty stopped finding juicy-berries. The days grew short and brisk while the nights grew long and cold. As he had expected, Morty's friends repaid their favors. Just when Morty was getting cold and hungry, Bartholomew Bunny brought him some yummy carrot stew. Then, just when his arms were getting chilled, Priscilla Partridge brought him a beautiful coat she had sewn for him. Morty rested in his comfy mouse-house, and he was happy.

[In version 2, "Calculating Loser," version 4, "Subtly Calculating Loser," and version 6, "Indiscriminate Loser," the italicized section is replaced with: Morty's friends failed to show up as expected, but even though Morty had no grain to keep his tummy full and no sweater to keep his arms warm, he was cozy in his mouse-house. His heart was warm, and he was happy.]

Part A: Please answer the following questions regarding the story you have just read:

1. If you had/have children of the appropriate age, how likely would you be to read this story to them? (answer 1 to 10, 1 being "definitely would not read" and 10 being "definitely would read")

2. Please describe why.

3. How entertaining do you think the story you just read would be for children of the appropriate age? (answer 1 to 10, 1 being "least entertaining" and 10 being "most entertaining")

Part B: Please indicate the following information about yourself

1. Your current age in years

2. Your gender (male/female)

3. Please indicate your current marital status from the following options: single, cohabiting, married, divorced/separated, widowed

4. Do you currently have any children?

5 . If your answer was yes, how many children do you have?

6. If your answer was yes, then please indicate the following for each child: age, gender, relation (biological, step, adopted)

\section{REFERENCES CITED}

Alexander, R. 1987. The biology of moral systems. New York: Aldine de Gruyter. 2005. "Evolutionary selection and the nature of humanity" in Darwinism and philosophy. Edited by V. Hosle and C. Illies, pp. 301-48. Purdue: University of Notre Dame Press. 
Barber, N. 2004. Kindness in a cruel world: The evolution of altruism. Amherst, NY: Prometheus Books.

Barongo, E. 1997. East Africa silent partners. UNESCO Courier 50(7-8):10-13.

Basso, K. 1990. Western Apache language and culture: Essays in linguistic anthropology. Tucson: University of Arizona Press.

Benjamin, W. 1973. Illuminations. London: Fontana Press.

Bernard, H. R. 1994. Research methods in anthropology: Qualitative and quantitative approaches. Thousand Oaks, CA: Sage Publications.

Bettelheim, B. 1976. The uses of enchantment: The meaning and importance of fairy tales. New York: Knopf.

Brown, D. 1991. Human universals. New York: McGraw-Hill.

Calame-Griaule, G. 1986. Words in the Dogon world. Philadelphia: Institute for the Study of Human Issues.

Carpenter, H. 1985. Secret gardens: A study of the golden age of children's literature. Boston: Houghton Mifflin.

Carrier, J. G. 1987. "Marine tenure and conservation in Papua New Guinea: Problems in interpretation," in The question of the commons: The culture and ecology of communal resources. Edited by B. J. McCay and J. M. Acheson, pp. 142-71. Tucson: University of Arizona Press.

Cochran, W. G. 1954. Some methods for strengthening the common chi-square tests. Biometrics 10:417-51.

Coe, K. 2003. The ancestress hypothesis. Newark: Rutgers University Press.

Coe, K., and C. T. Palmer. 2006. The words of our ancestors: Kinship, tradition, and moral codes. World Cultures 16(1). (in press)

Coe, K., N. Aiken, and C. T. Palmer. 2005a. Once upon a time: Ancestors and the evolutionary significance of stories. Anthropological Forum 16:21-40.

Coe, K., C. T. Palmer, K. Aiken, and C. Cassidy. 2005b. The role of traditional children's stories in human evolution. Entelechy: Mind and Culture 6 (fall/winter). $<$ www.entelechyjournal.com>

Cohn, D. 1978. Transparent minds: Narrative modes for presenting consciousness in fiction. Princeton: Princeton University Press.

Daly, M., and M. Wilson. 1999. The truth about Cinderella: A Darwinian view of parental love. New Haven: Yale University Press.

De Laguna, F. 1997. Under Mount Saint Elias: The history and culture of the Yakutat Tlingit. Washington, DC: Smithsonian.

Drennan, R. D. 1996. Statistics for archaeologists: A commonsense approach. New York: Plenum Press.

Elkin, A. P. 1964. The Australian Aborigines. Garden City: Doubleday.

Gottschall, J. 2002. Traits of female protagonists and antagonists in world folktales. Paper presented at the Human Behavior and Evolution Society conference, June 19-23, Rutgers University.

- 2003. Patterns of characterization in folk tales across geographic regions and levels of cultural complexity: Literature as a neglected source of quantitative data. Human Nature 14:365-82.

- 2005. "Quantitative literary study, Part I: A modest manifesto" and "Part II: Testing the hypotheses of feminist fairy tale studies," in The literary animal: Evolution and the nature of narrative. Edited by J. Gottschall and D. S. Wilson, pp. 199-224. Evanston, IL: Northwestern University Press. 
Gottschall, J., E. Allison, J. De Rosa, and K. Klockeman. 2006. Can literary study be scientific? Results of an empirical search for the virgin-whore dichotomy. Interdisciplinary Literary Studies 7(2):1-17.

Gottschall, J., J. Martin, H. Quish, and J. Rea. 2004. Sex differences in mate choice criteria are reflected in folktales from around the world and in historical European literature. Evolution and Human Behavior 25(2):102-12.

Hamilton, V. 1997. Ring of tricksters: Animal tales from America, the West Indies, and Africa. Singapore: Blue Sky Press.

Hefner, P. 1991. Myth and morality: The love command. Zygon 26:115-36.

Henrich, J., and R. Boyd. 1998. The evolution of conformist transmission and the emergence of between-group differences. Evolution and Human Behavior 19:215-41.

Henrich, J., R. Boyd, S. Bowles, C. Camerer, E. Fehr, H. Gintis, R. McElreath, M. Alvard, A. Barr, J. Ensminger, N. S. Henrich, K. Hill, F. Gil-White, M. Gurven, F. Marlowe, J. Patton, and D. Tracer. 2005. "Economic man" in cross-cultural perspective: Behavioral experiments in 15 small-scale societies. Behavioral and Brain Sciences 28:795-855.

Hunt, P. 1999. "Introduction: The world of children's literature studies," in Understanding children's literature. Edited by P. Hunt, pp. 1-14. London: Routledge.

Ishii, K., and R. Kurzban. 2005. Real-time public goods in Japan: Cultural and individual differences in trust and reciprocity. Unpublished ms. in the authors' possession.

Kirk, D. 2003. Miss Spider's Sunny Patch Kids. HIT Entertainment.

Kuokkanen, R. 1998. Restory-ing the Sami strength. ReVision 21(1):11-14.

Malinowski, B. 1931. "Culture," in Encyclopedia of the Social Sciences, vol. IV. Edited by E. R. Seligman and A. S. Johnson, pp. 634-42. New York: Macmillan.

Maynard Smith, J. 1984. Science and myth. Natural History (November):11-24.

Palmer, C. T. 1991. Kin-selection, reciprocal altruism and information sharing among Maine lobstermen. Ethology and Sociobiology 12:221-36.

Paul, L. 1990. "Enigma variations: What feminist theory knows about children's literature," in Children's literature: The development of criticism. Edited by P. Hunt, pp. 148-66. London: Routledge.

Pinker, S. 1997. How the mind works. New York: W. W. Norton.

Piumini, R. 1989. Aesop's fables. Italy: Barron's Educational Series.

Quattrocki, C. 1995. Treasury of bedtime stories. Lincolnwood: Publications International. Rackham, A., ed. 1974. Fairy tales from many lands. New York: Viking Press.

Ridley, M. 1996. Origins of virtue: Human instincts and the evolution of cooperation. New York: Penguin Books.

Rose, M. R., and J. H. Altschul. 1988. "An overview of statistical method and theory in quantitative model building," in Quantifying the present and predicting the past: Theory, method, and application of archaeological predictive modeling. Edited by W. J. Judge and L. Sebastian, pp. 173-255. Denver: U.S. Department of the Interior, Bureau of Land Management.

Sarland, C. 1999. "The impossibility of innocence: ideology, politics, and children's literature," in Understanding children's literature. Edited by P. Hunt, pp. 39-55. London: Routledge.

Scalise Sugiyama, M. S. 2001a. Narrative theory and function: Why evolution matters. Philosophy and Literature 25:233-50.

$2001 \mathrm{~b}$. Food, foragers, and folklore: The role of narrative in human subsistence. Evolution and Human Behavior 22:221-40.

- 2002. Lions and tigers and bears: Predators as a folklore universal. Paper presented at the Human Behavior and Evolution Society conference, June 19-23, Rutgers University. 
Scott, D. H. 1980. Chinese popular literature and the child. Chicago: American Library Association.

Shennan, S. 1990. Quantifying archaeology. San Diego: Academic Press.

Shepherd, S. 1995. Myths and legends from around the world. Italy: Macmillan Books for Young Readers.

Steadman, L. B., and C. T. Palmer. 1997. Myths as instructions from ancestors: The example of Oedipus. Zygon 32:341-50.

Steen, Francis F. 2005. The paradox of narrative thinking. Journal of Cultural and Evolutionary Psychology 3(1):87-105.

Steen, F., and S. Owens. 2001. Evolution's pedagogy: An adaptationist model of pretense and entertainment. Journal of Cognition and Culture 1(4):289-321.

Thomas, D. H. 1986. Refiguring anthropology: First principles of probability and statistics. Prospect Heights, IL: Waveland Press.

Tooby, J., and L. Cosmides. 1992. "Psychological foundations of culture," in The adapted mind. Edited by J. Barkow, L. Cosmides, and J. Tooby, pp. 19-136. New York: Oxford University Press.

- 2001. Does beauty build adapted minds? Toward an evolutionary theory of aesthetics, fiction and the arts. SubStance 94/95 30(1):6-27.

Trivers, R. 1971. The evolution of reciprocal altruism. Quarterly Review of Biology 46:35-56.

Vaughn, T. 1978. Mammalogy. Philadelphia: Saunders College Publishing.

West, M. I. 1999. "Guilt and shame in early American children's literature," in Psychoanalytic responses to children's literature. Edited by L. Rolling and M. I. West, pp. 151-58. Jefferson, NC: McFarland.

Wooden, W. W. 1986. Children's literature of the English Renaissance. Lexington: University of Kentucky Press.

Zipes, Jack. 1991. Fairy tales and the art of subversion. New York: Routledge. 